\title{
Ion Source for Radioactive Isotopes - IRIS ECR
}

\section{J. T. Burke ${ }^{1,2}$, S.J. Freedman ${ }^{1,2}$, C.M. Lyneis ${ }^{1,2}$, D. Wutte ${ }^{2}$}

A compact electron cyclotron resonance ion source for radioactive isotopes (IRIS ECR) has been developed for the ${ }^{14} \mathrm{O}$ experiment at the $88^{\prime \prime}$ Cyclotron. The ${ }^{14} \mathrm{O}$ experiment is a joint effort between the Nuclear Science Division's Weak Interaction Group and the 88-Inch Cyclotron ECR ion source group. The initial goal of the experimentalists is to measure ${ }^{14} \mathrm{O}$ half-life and the shape of the beta decay spectrum. The 70 second half-life of ${ }^{14} \mathrm{O}$ requires producing the isotope online at the $88^{\prime \prime}$ Cyclotron. The ${ }^{14} \mathrm{O}$ is generated in the form of ${ }^{12} \mathrm{C}^{14} \mathrm{O}$ in a high temperature carbon aerogel target using a 20 $\mathrm{MeV}{ }^{3} \mathrm{He}^{+}$beam from the LBNL 88" Cyclotron via the reaction ${ }^{12} \mathrm{C}\left({ }^{3} \mathrm{He}, \mathrm{n}\right){ }^{14} \mathrm{O}$. The ${ }^{14} \mathrm{O}$ atoms are then separated from the other radioactive isotopes produced in the target and then implanted into a thin foil. The implanted target serves to minimize the radiation background and maximize the signal in the beta spectrometer by concentrating the ${ }^{14} \mathrm{O}$ into a $5 \mathrm{~mm}$ diameter spot.

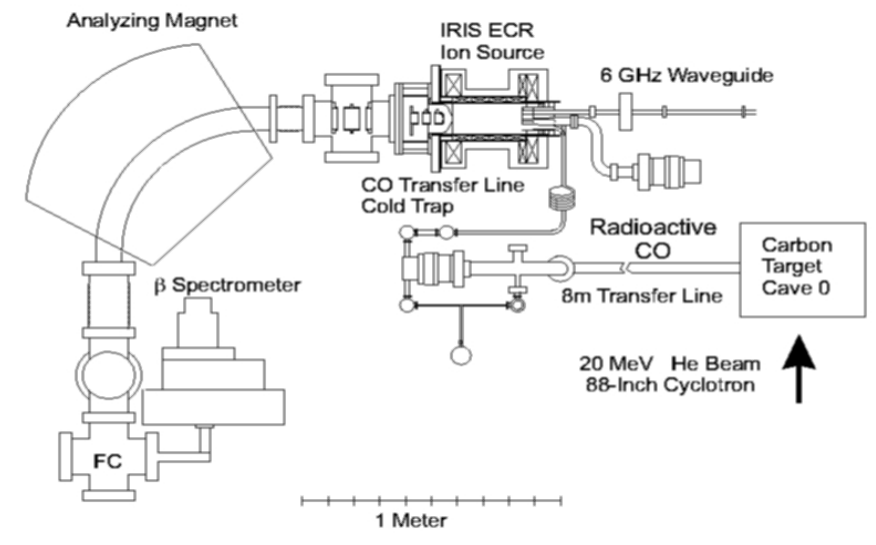

Fig. 1 The IRIS ECR and supporting hardware.

An 8 meter long stainless steel transfer line connects the the target chamber to the IRIS ECR through a turbo molecular pump, see figure 1 . The gas coming from the turbo pump is fed into the ion source and ionized, extracted at energies of 20 to $30 \mathrm{keV}$ and mass separated by an analyzing magnet.
The ion source started operation in spring 1999 and achieved a beam intensity of $3 \times 1{ }^{5}{ }^{14} \mathrm{O}^{+}$ions/second. Extensive developments on the production target were made to increase extraction efficiency of the ${ }^{14} \mathrm{O}$. A liquid nitrogen trap was installed between the ECR and the turbo pump to minimize the gas load to the ion source. An improved support gas injection system was installed so that multiple support gases can be introduced. A bias disk is used to stabilize the plasma. A quartz liner in the plasma chamber is used to reduce the hold-up time for oxygen and increase the overall ionization efficiency. The extraction system was also modified to ensure reliable operation at $30 \mathrm{kV}$.

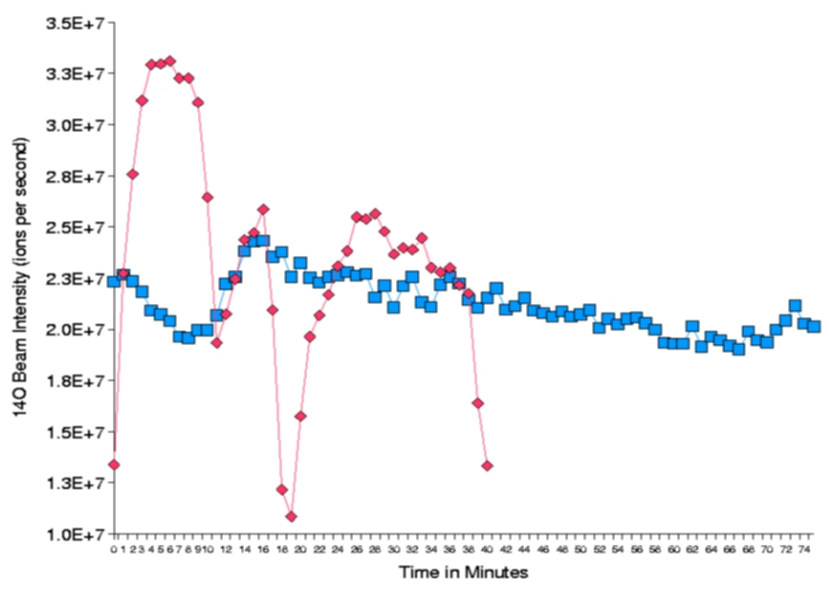

Fig. 2 The plot above shows a typical run in blue and the peak intensity run in red.

In May 2000 IRIS produced a mass separated beam of ${ }^{14} \mathrm{O}^{1+}$ ions at an average intensity of $2 \times 10^{74} \mathrm{O}^{1+}$ ions per second with a peak intensity of $3 \times 10^{14} \mathrm{O}^{1+}$ ions per second, see figure 2 . This is the highest ${ }^{14} \mathrm{O}$ intensity achieved at any radioactive beam facility to date. The physics program has begun with a measurement of the ${ }^{14} \mathrm{O}$ lifetime in October 2001 and a test run for the CVC experiment during December 2001 ( in these reports J.T. Burke).

Footnotes 1 Physics Department University of California Berkeley 2 Nuclear Science Division Lawrence Berkeley National Laboratory 